\title{
Human Factors Aspects in Set-Up Time Reduction
}

\author{
Dirk Van Goubergen ${ }^{1}$ and Thurmon E. Lockhart ${ }^{2}$ \\ I) Ghent University, Department of Industrial Management, Zwijnaarde B-9052, Belgium. \\ Email:dirk.vangoubergen@UGent.be \\ 2) Grado Department of Industrial and Systems Engineering, Virginia Polytechnic Institute \\ and State University, Blacksburg 24061, VA, USA. \\ Email:lockhart@vt.edu.
}

\begin{abstract}
The ability to produce products which continue to meet changing customer expectations requires flexibility within a manufacturing plant. Short set-up times are a key enabler for obtaining these flexible production systems. The purpose of this research is to identify human factors issues in set-up reduction and to develop a framework for assessing and improving the changeover from an ergonomics point of view. A Human Factors System Design methodology will be the starting point to identify how the existing human factors body of knowledge can be incorporated in the body of knowledge of design for fast changeover. This publication describes the first steps of this research. We identify the human factors gaps and deficiencies in the current set of design rules for fast changeover.
\end{abstract}

Key words: Fast changeover, Human factors system design, Design rules

\section{INTRODUCTION}

\subsection{Why Set-up Time Reduction?}

Although the need for short set-up times is not new, recently in all types of industry an increased focus on set-up times is perceived. The need for short set-ups is now bigger than ever. Globalization of the market, customization of products and the continuous effort for better efficiency of the existing production equipment are the main driving forces for this phenomenon. (VAN GOUBERGEN 2000, p. 1) 
Many companies around the world are implementing lean concepts and customer-pull based production systems. For these systems short set-up times are a sine qua non (WOMACK, JONES 1996, p. 26).

\subsection{Existing Set-up Reduction Methodologies}

There are several publications and case studies available on how set-up times can be reduced in existing situations (SHINGO 1985; see also VAN GOUBERGEN, VAN LANDEGHEM 2002). Basically all approaches are derived from the SMED method ("Single Minute Exchange of Die") (SHINGO 1985). According to the SMED method all activities related to a set-up can be divided into internal - which are performed while the machine is down and thus the production process is stopped - and external - which take place while the machine is running activities.

Actually, in practice a lot of set-up problems could have been avoided if the machine designer would have paid proper attention to the set-up problem. Several set-up reduction principles from the SMED method, as well as the use of specific industrial engineering techniques, can be applied during the design stage of machines and equipment. However, very limited research has been published on how to incorporate fast changeover capabilities in machine design.

An initial set of design rules is published by (MILEHAM et al. 1999). Most of these rules were technical in nature. This list was substantially extended by (VAN GOUBERGEN, VAN LANDEGHEM 2002) based on practical experience with more than 60 set-up reduction projects on different types of machines in different types of industry. The resulting list of rules include rules dealing with technical as well as organizational or method aspects.

\subsection{Goal of this Research - Human Factors Aspects}

The principles and rules that are mentioned in the previous section have been proven to be successful in many situations in different types of industry (for examples see VAN GOUBERGEN, VAN LANDEGHEM 2002, p. 213). However, when they were established, the main focus has been on the "time" aspect: how to reduce the machine downtime or the internal/on-line time.

Human factors aspects are only included in an implicit way and are not studied in depth, although it is obvious that humans play a crucial role in setups. We strongly believe that the existing body of knowledge on human factors can offer interesting additional insights and ways to improvement of 
set-ups. An in-depth search of human factors and ergonomics literature has not given one single publication on this subject.

Therefore, the main overall goal of this research is to assess set-ups from a human factors point of view and to propose additional human factors based rules for finding appropriate improvement proposals in order to shorten setup times. We identified following research steps to reach our research goal:

1. Identify human factors gaps and deficiencies in current set of design rules (i.e. which human factor elements are not covered yet?).

2. Based on the results of the first step, develop additional comprehensive rules that can be used by the practitioner and that complete the existing list of design rules for fast changeover.

3. Refine the current, existing rules using the human factors body of knowledge. We will identify:

- Which rules need to be extended?

- Which rules can be more detailed?

4. Validate the new rules with experiments.

5. Develop an assessment framework based on the human factors body of knowledge in order to identify opportunities to reduce set-up times by improving human factors aspects in case of existing set-up methods.

This publication presents the results of the first step of this research: identify human factors related gaps in the existing set-up reduction approaches and design rules by using a universal human factors system model. Based on these results we will also provide some input for the second research step.

\section{HUMAN FACTORS SYSTEM MODEL}

Current design rules mentioned in section 1.2 were mapped to the appropriate section of an adapted version of the "Human Factors in Systems Design" model (HELANDER 1997; see Figure 1), to see what parts of the human factors design paradigm were missing from current fast-changeover design guidelines. This model was chosen because of its completeness. For all elements of the model an operational definition was documented that is suitable for use in the context of set-up time reduction. Some examples can be found in Table 1.

Next, every existing design rule for fast changeover was mapped under these elements. In total there were 52 design rules divided amongst 9 categories. Table 2 provides an overview of these categories and the number of rules in each category. 


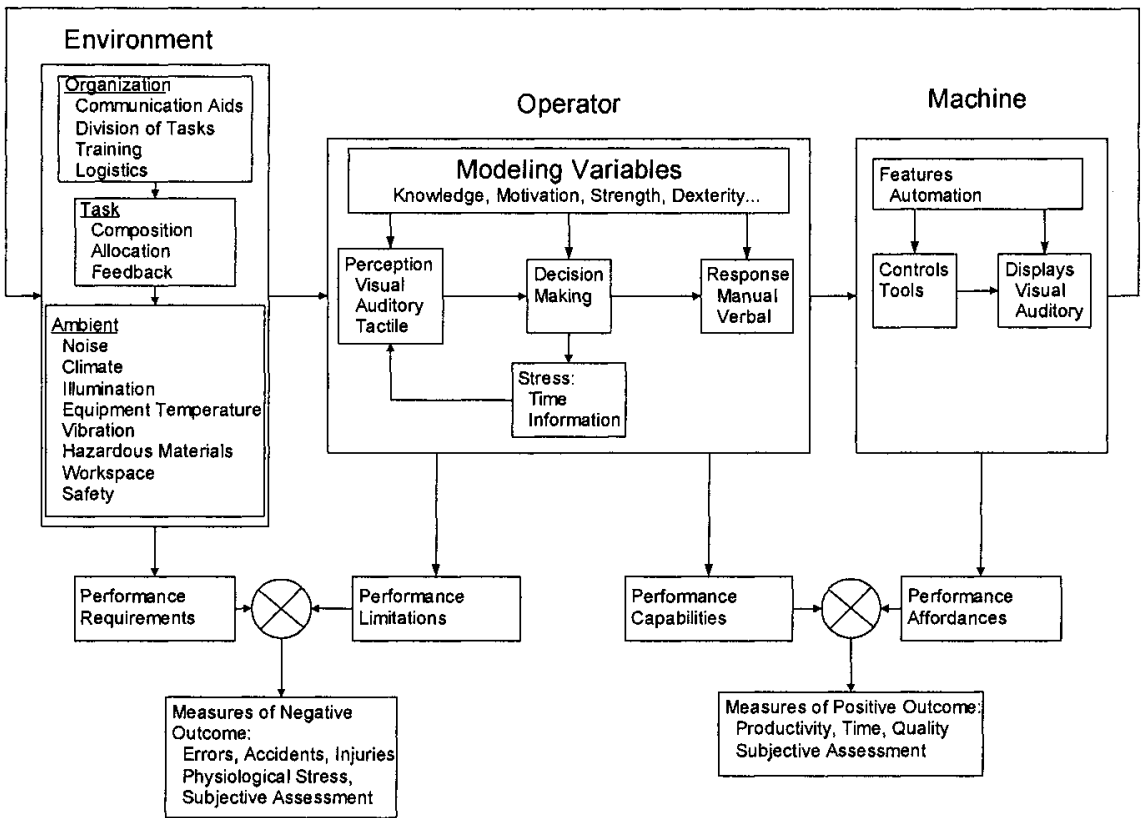

Figure 1, "Human Factors Systems Design" model

(HELANDER 1997)

The results of the mapping were visualized using histograms indicating how many rules fall under each element from the "Human Factors System Design" model. Figure 2 shows as an example the histogram portraying the number of rules that are related to the elements related to the operator in the "Human Factors System design" model. Similar diagrams were made for the elements in the categories "Environment" and "Machine".

Table 1. Examples of the operational definition of the elements of the "Human Factors System Design" model adapted for use in the context of set-up reduction

\begin{tabular}{|c|c|}
\hline Element & Definition \\
\hline Division of tasks & $\begin{array}{l}\text { Organization of changeover tasks and optimal division among } \\
\text { changeover personnel }\end{array}$ \\
\hline Task composition & $\begin{array}{l}\text { Changing the nature of the task (i.e. changing from a bolt fixture } \\
\text { to a clamp fixture) }\end{array}$ \\
\hline Equipment temperature & $\begin{array}{l}\text { The temperature of parts of the machine being changed, includ- } \\
\text { ing areas that must be accessed to perform the changeover }\end{array}$ \\
\hline Strength & $\begin{array}{l}\text { Required muscular strength of the operator needed to perform } \\
\text { the changeover }\end{array}$ \\
\hline Visual display & Visual information output from the machine \\
\hline
\end{tabular}


Table 2. Overview of the categories of existing design rules

\begin{tabular}{lc}
\hline Category & Number of rules \\
\hline Less weight & 2 \\
Simplification & 10 \\
Standardization & 3 \\
Securing & 5 \\
Location and adjustment & 15 \\
Handling & 8 \\
Off-line activities & 2 \\
Machine lines & 1 \\
Method and organization & 7 \\
\hline
\end{tabular}

In mapping these rules, the direct human factors impact of the rule was inferred. The human factors literature was consulted to develop general guidelines for incorporating human factors principles in the design.

\section{HF System Design Model - Eements related to the Operator}

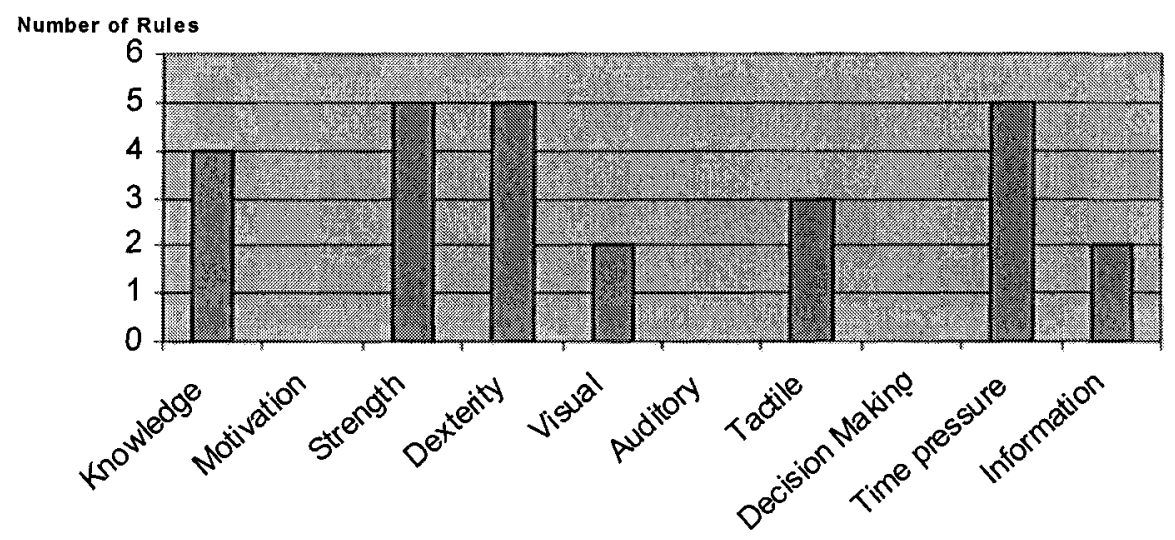

Figure 2. Example of the results of the mapping of design rules:

The number of design rules related to the elements of the category "Operator" in the "Human Factors System Design" model

\section{RESULTS}

Several human factors issues are under represented or not represented at all in the current design rules. Based on evaluation of the current rules, the following human factors issues are not adequately addressed: 
1. Communication aids

2. Task allocation

3. Noise

4. Climate

5. Illumination

6. Vibration

7. Hazardous materials
8. Motivation

9. Auditory perception

10. Decision making

11. Automation

12. Visual displays

13. Auditory displays

14. Safety

Short synapses of the results section is presented below:

- Communication aids:

Communication is extremely important for changeovers that require the coordinated effort of a team. In some instances, the use of simple displays, such as andon lights, can aid communication. Additionally, the general rule should be to avoid the requirement for remote support (WHITAKER, FOX, PETERS 1993).

- Task allocation and automation:

Proper allocation of tasks is necessary to produce an optimal system. A rule should be added to remind the designer to consider the options of human and machine operations during machine design. Decision criteria for automation have already been developed and should be employed (OLDER, WATERSON, CLEGG 1997). In practice the decision for automation will be based on a cost/benefit analysis. It is important to not limit the cost analysis to the engineering or purchasing cost. A life cycle cost analysis is more appropriate as in a lot of situations an important part of the operational costs will be the downtime cost due to changeovers. Trade-offs can be made with regard to the degree of automation and the associated design cost versus the reduction of set-up downtime costs. On the other hand, due to the ever more complex manufacturing environment and the flexibility of human operators, complete automation is often infeasible (AYRES, BUTCHER 1993).

- Noise and auditory perception:

As a general rule, noise should be kept to a minimum. Noise in the external environment also contributes to the local noise level, so a more systemic approach is necessary to effectively reduce noise levels.

- Climate:

Some studies have shown that heat decreases mental awareness, increases stress on the human body and can even affect a human operator in psychological ways (NIOSH 1986). VAN GOUBERGEN, VAN LANDEGHEM (2002) propose that motivation is a pillar of producing quick set-ups. Therefore, the psychological affects of working in heat should not be ignored. 


\section{- Illumination:}

The amount of ambient illumination has several effects on work systems. Visual fatigue can set in if the work area is too bright or too dim. If so, this can reduce the operator's capability to observe accurately and can decrease the desire to perform accurately. This can be detrimental to the set-up process, as can the misreading of visual cues.

- Vibration:

The human body resonates at certain frequencies. It is theorized that physical damage due to vibration occurs when the human body is in a state of resonate amplification. Therefore, in addition to reducing vibration in general, there are certain frequency ranges to avoid (WASSERMAN 1987).

- Hazardous materials and safety:

Current design rules for fast changeover also neglect explicitly to cover many safety issues that face the operator.

- Motivation:

VAN GOUBERGEN and VAN LANDEGHEM (2002) propose that motivation is the foundation of achieving a fast changeover. Although the culture of the organization is crucial here, machine designers can influence motivation by designing the machine to be easily maintained and set-up in a comfortable way.

- Decision-making aids:

On-board diagnostic equipment can greatly reduce the post-set-up adjustment process. Practice shows that even in cases where a standardized set-up method is available and documented in a set-up instruction, insufficient attention is paid to the re-adjustment process. If a trial run shows that there is a non conformance on one (or more) of the product requirements, it can often be seen that each operator tries to solve this problem in a different way. Decision making aids are needed to show the relationship between product requirements and setting parameters. This way, based on how much deviation there is on the product specification, one knows which parameter needs to be re-adjusted and how much.

- Visual and auditory displays:

The design of displays is very important to achieve settings that are right the first time. A lot of machines nowadays are still lacking good adjustment aids such as displays. In that case the setting activity will not be based on measurements, but more on trial and error. Depending on the type of parameter that needs to be set and the required accuracy, an appropriate display needs to be designed. The human factors body of knowledge already contains in-depth information on the design of displays in order to portrayal information. This knowledge can add specific guidelines for this design. 
To remedy these gaps in the current set of design rules, new rules need to be added. However, we must keep in mind what the "sphere of control" of the machine designer consists of. He does determine both the concept and the practical realization of the machine. On the other hand, he is not in control of environmental factors and ambient elements of the workplace where the machine is going to be used. So it is of no use to add specific design rules for some of these issues.

Also, some of the missing elements that are discussed in the previous paragraph relate to more general principles and guidelines for machine design and are not directly related to the changeover problem. For example guidelines regarding basic safety issues on machines apply to all machine designs and are usually already available. Therefore they do not need to be added to a specific list of design rules dealing with fast changeover.

\section{CONCLUSION}

Current design rules for fast changeover neglect the principles of humancentered design. This study has identified the human-related shortcomings of these rules. The next step in this research will be to use the human factors body of knowledge to modify existing rules and add more in-depth rules.

\section{REFERENCES}

AYRES, R. U.; BUTCHER, C. D.:

The flexible factory revisited.

In: American Scientist,

Triangle Park, NC, 8(1993)5, pp. 448-459.

HELANDER, M. G.:

The Human Factors Profession.

In: Handbook of Human Factors and Ergonomics.

Ed.: SALVENDY, G.

New York, NY: John Wiley and Sons, 2nd ed., 1997, pp. 3-16.

MILEHAM, A. R.; CULLEY, S. J.; OWEN, G. W.; McINTOSH, R.:

Rapid Changeover - a pre-requisite for responsive manufacture.

In: International Journal of Operations and Production Management,

Bradford, 19(1999)8, pp. 785-796.

NIOSH:

Working in hot environments.

Washington, DC: National Institute for Occupational Safety and Health.

(DHHS (NIOSH) Publication No. 86-112) 
OLDER, M. T.; WATERSON, P. E.; CLEGG, C. W.:

Critical assessment of task allocation methods and their applicability.

In: Ergonomics,

London et al., 40(1997)2, pp. 151-171.

SHINGO, S.:

A Revolution in Manufacturing: The SMED System.

Cambridge, MA: Productivity Press, 1985.

VAN GOUBERGEN, Dirk:

Set-up reduction as an organization-wide problem.

In: Proceedings of Solutions 2000 Conference. Norcross, GA:

Institute of Industrial Engineers, 2000.

CD-ROM.

VAN GOUBERGEN, D.; VAN LANDEGHEM, H.:

Rules for integrating fast changeover capabilities into new equipment design.

In: Robotics and Computer Integrated Manufacturing,

Oxford et al., 18(2002)3, pp. 205-214.

WASSERMAN, D.E.:

Motion and vibration.

In: Handbook of Human Factors and Ergonomics.

Ed.: SALVENDY, G.

New York, NY: John Wiley and Sons, 2nd edition, 1997, pp. 650-669.

WOMACK, J. P.; JONES, D. T.:

Lean thinking.

London et al.: Simon and Schuster, 1996.

WHITAKER, L. A.; FOX, S. L.; PETERS, L. J.:

Communication between crews: the effect of speech intelligibility on team performance.

In: Proceedings of the Human Factors and Ergonomics Society. 37th Annual Meeting.

Santa Monica, CA: Human Factors and Ergonomics Society, 1993, pp. 630-634. 